\title{
Unifying mechanism in the initiation of breast cancer by metabolism of estrogen (Review)
}

\author{
CHUNJIE WEN ${ }^{1}$, LANXIANG WU ${ }^{1}$, LIJUAN FU ${ }^{2}$, BING WANG ${ }^{1}$ and HONGHAO ZHOU ${ }^{1}$ \\ Institutes of ${ }^{1}$ Life Sciences and ${ }^{2}$ Traditional Chinese Medicine, Chongqing Medical University, Chongqing 400016, P.R. China
}

Received June 18, 2016; Accepted March 23, 2017

DOI: $10.3892 / \mathrm{mmr} .2017 .6738$

\begin{abstract}
Excessive exposure to estrogen is associated with increased risk of breast cancer. The mechanisms of carcinogenesis in the breast caused by estrogen metabolism include formation of depurinating adducts which are released from DNA to generate apurinic sites, and production of reactive oxygen species (ROS). Excess ROS not only exerts genotoxicity by indirectly increasing genomic instability, but also stimulates progression of mammary carcinogenicity by inducing a redox-associated signaling pathway. Estrogen metabolism enzymes serve an important role in estrogen metabolism. Alterations in the expression and activity of estrogen metabolism enzymes may influence estrogen metabolism homeostasis. The present review discusses the process of estrogen metabolism, the role of estrogen metabolites and ROS in breast carcinogenesis, and the effect of metabolism enzyme polymorphisms on generation of pro-carcinogens and breast cancer susceptibility.
\end{abstract}

\section{Contents}

1. Introduction

2. Estrogen metabolism

3. Role of estrogen and its metabolites in carcinogenesis

4. Role of ROS in estrogen carcinogenesis

5. Association of metabolism enzyme polymorphisms in breast cancer

6. Conclusion

\section{Introduction}

Breast cancer is one of the most common malignancies among females worldwide (1). Estrogens have been implicated in the

Correspondence to: Professor Honghao Zhou, Institute of Life Sciences, Chongqing Medical University, 1 Xueyuan Road, Chongqing 400016, P.R. China

E-mail: hhzhou2003@163.com

Key words: estrogen, metabolism, reactive oxygen species, breast cancer etiology of breast cancer. Epidemiological and clinical evidence has indicated that factors associated with elevated estrogen levels throughout the lifetime of a female, including the early onset of menstruation, late menopause, use of oral contraceptives, late first full-term pregnancy, and hormone replacement therapy, are associated with an increase in breast cancer risk among pre- and postmenopausal women (2). Estrogens are generally considered to cause proliferation of breast cancer cells via the estrogen receptor (ER), and serve as a transcription factor to regulate the expression of target genes encoding proteins with important biological functions (3). The ER-mediated signaling pathway may have an important role in the development of cancer; however, they do not serve a crucial role in cancer initiation (4). Compared with ER-mediated processes, substantial evidence suggests that the oxidative metabolism of estrogens serves a major role in the initiation of breast cancer $(5,6)$. Specific estrogen metabolites, predominantly catechol estrogens-3,4-quinones (CE-3,4-Q), have the potential to initiate the cancer process by binding to DNA and forming depurinating adducts, $4-\mathrm{OHE}_{1}\left(\mathrm{E}_{2}\right)-1-\mathrm{N} 3 \mathrm{Ade}$ and $4-\mathrm{OHE}_{1}\left(\mathrm{E}_{2}\right)-1-\mathrm{N} 7 \mathrm{Gua}(6,7)$. These depurinating DNA adducts are rapidly lost from DNA by cleavage of the glycosyl bond, leaving apurinic sites in DNA that may generate mutations that initiate cancer (8). In addition, redox cycling of quinone and semiquinone metabolites results in the generation of free radicals and reactive oxygen species (ROS). Excessive ROS not only exerts genotoxicity by indirectly increasing genomic instability, but also stimulates progression of mammary carcinogenicity by transducing redox-associated signal pathways $(9,10)$.

Estrogen metabolism and elimination can be characterized by two steps. Phase is the conversion of estrogen into CEs by cytochrome P450 (CYP) 450 enzymes. The major P450 enzymes involved in estrogens metabolize include CYP1A1 and CYP1B1. Phase II is the inactivation and detoxification pathways of CEs, including O-methylation by catechol-O-methyltransferase (COMT). The present review discusses the process of estrogen metabolism, the role of estrogen metabolites and ROS in breast carcinogenesis, and the effect of metabolism enzyme polymorphisms on generation of procarcinogens and breast cancer susceptibility.

\section{Estrogen metabolism}

Endogenous estrogen mainly refers to estrone $\left(E_{1}\right)$ and $17 \beta$-estradiol $\left(E_{2}\right) . E_{1}$ and $E_{2}$ are interconverted by 
$17 \beta$-hydroxy steroid dehydrogenase (17ß-HSD; Fig. 1) (11). Endogenous estrogens are metabolized by two main pathways: Formation of the 2-OH- and 4-OH-estrogens, which are known as CEs, and to a lesser extent, $16 \mathrm{a}-\mathrm{OHE}_{1}\left(\mathrm{E}_{2}\right)(11)$. CYP3A5, CYP3A7and CYP1A1 have catalytic ability for $16 \mathrm{a}-\mathrm{OHE}_{1}\left(\mathrm{E}_{2}\right)(11)$. In extrahepatic tissues, estrogens are transformed into $2-\mathrm{OHE}_{1}\left(\mathrm{E}_{2}\right)$ by CYP1A1, whereas $4-\mathrm{OHE}_{1}\left(\mathrm{E}_{2}\right)$ is catalyzed primarily by CYP1B1 (11). Since CYP1B1 has been demonstrated to be expressed in healthy human breast ductal tissue and over-expressed in invasive ductal carcinomas, estrogen-quinone depurinating adducts levels are greater in women with breast cancer compared with healthy women $(4,12-14)$.

In extrahepatic tissues, the most common pathway of conjugation of CEs is O-methylation inactivation via COMT, which prevents their conversion to estrogen semiquinones and quinines (15). COMT catalyzes $2-\mathrm{OHE}_{1}\left(\mathrm{E}_{2}\right)$ at the $2-\mathrm{OH}$ and $3-\mathrm{OH}$ positions, and $4-\mathrm{OHE}_{1}\left(\mathrm{E}_{2}\right)$ at the $4-\mathrm{OH}$ position, with the methyl group derived from S-adenosylmethionine (16). Inhibition of COMT increases the amount of oxidative DNA damage and 4-OH quinine depurinating adduct levels, which means that COMT is responsible for preventing the oxidative metabolism of CEs to genotoxic quinone metabolites $(17,18)$. Previous studies have suggested that 2-methoxyestradiol, the major O-methylation metabolite of 2- $\mathrm{OHE}_{1}\left(\mathrm{E}_{2}\right)$, has anticancer activities by growth inhibitory effects (19).

Unless detoxified, 2- $\mathrm{OHE}_{1}\left(\mathrm{E}_{2}\right)$ and 4- $\mathrm{OHE}_{1}\left(\mathrm{E}_{2}\right)$ are further oxidized to the corresponding quinones, $\mathrm{E}_{1}\left(\mathrm{E}_{2}\right)-2,3-\mathrm{Q}$ and $E_{1}\left(E_{2}\right)-3,4-Q$. Of the two estrogen quinones, $E_{1}\left(E_{2}\right)-3,4-Q$ is believed to be a critical metabolite which reacts with DNA to form depurinating adducts. Quinones also undergoes a two-electron reduction to form corresponding hydroquinones, which are transformed by $\mathrm{NAD}(\mathrm{P}) \mathrm{H}-\mathrm{Quinone}$ oxidoreductase 1 (NQO1) (20). NQO1 transforms CE-Q back to CEs, thus making quinone metabolites unavailable for reaction with DNA and oxidative stress (20).

\section{Role of estrogen and its metabolites in carcinogenesis}

Chemical carcinogens covalently bind to DNA to generate two types of adducts: stable ones and depurinating ones. $\mathrm{E}_{1}\left(\mathrm{E}_{2}\right)-3,4-\mathrm{Q}$ produces much higher levels of depurinating adducts and smaller amounts of stable adducts (7). Depurinating estrogen-DNA adducts serve an important role in cancer initiation. The depurinating adducts are rapidly lost from DNA by cleavage of the glycosyl bond, and then produce apurinic sites that may lead to cancer (21). Mounting experiments on estrogen metabolism, formation of DNA adducts, carcinogenicity, mutagenicity and cell transformation has identified that estrogen metabolites, especially CE-3,4-Q, react with DNA to form predominantly depurinating adducts, $4-\mathrm{OHE}_{1}\left(\mathrm{E}_{2}\right)$ -1-N3Ade and 4- $\mathrm{OHE}_{1}\left(\mathrm{E}_{2}\right)-1-\mathrm{N} 7 \mathrm{Gua}$, leading to the accumulation of mutations and potentially cell transformation $(6-8,22)$. 2- $\mathrm{OHE}_{1}\left(\mathrm{E}_{2}\right)$ is transformed to $\mathrm{E}_{1}\left(\mathrm{E}_{2}\right)-2,3-\mathrm{Q} ; \mathrm{E}_{1}\left(\mathrm{E}_{2}\right)-2,3-\mathrm{Q}$ is much less reactive with DNA than $\mathrm{E}_{1}\left(\mathrm{E}_{2}\right)-3,4-\mathrm{Q}$, because different mechanisms of adduction are responsible for different reactivity. $\mathrm{E}_{1}\left(\mathrm{E}_{2}\right)-3,4-\mathrm{Q}$ reacts via a proton-assisted 1,4-Michael addition; however, reaction of $\mathrm{E}_{1}\left(\mathrm{E}_{2}\right)-2,3-\mathrm{Q}$ with Ade results in the generation of $2-\mathrm{OHE}_{1}\left(\mathrm{E}_{2}\right)-6-\mathrm{N} 3 \mathrm{Ade}$ by 1,6 -Michael addition $(23,24)$. The greater carcinogenic activity of 4- $\mathrm{OHE}_{1}\left(\mathrm{E}_{2}\right)$ is associated with a higher amount of depurinating DNA adducts formed by $\mathrm{E}_{1}\left(\mathrm{E}_{2}\right)-3,4-\mathrm{Q}$, compared with $\mathrm{E}_{1}\left(\mathrm{E}_{2}\right)-2,3-\mathrm{Q}(25)$. According to previous studies, 2- $\mathrm{OHE}_{1}\left(\mathrm{E}_{2}\right)$ methylation by COMT may have an inhibitory effect on cell proliferation (19). This may be another reason for the reduced genotoxic of 2-OHE $\left(\mathrm{E}_{2}\right)$.

Accumulating evidence for the initiation of cancer by estrogen-DNA adducts has been identified by using human breast epithelial cell lines such as MCF-10F, which is an immortalized, non-transformed ER-a-negative cell line. Treatment of these cells with $\mathrm{E}_{2}$ or $4-\mathrm{OHE}_{2}$ produces depurinating estrogen-DNA adducts (26-28). These adducts induce colony formation in soft agar, the expression of which are indicative of neoplastic transformation ability. (29-31). The cells are transformed by estrogens even in the presence of the anti-estrogen tamoxifen or ICI-182,780 (31). The results further indicate that transformation occurs via the genotoxic effects of the estrogen metabolites. The 2- $\mathrm{OHE}_{2}$ metabolite induces these alterations to a much smaller extent. Implantation of estrogen-transformed MCF-10F cells, selected by their invasiveness, into severely compromised immune-deficient mice, produces tumors (30). Female ERKO/Wnt-1 mice were ovariectomized at 15 days old and implanted with $\mathrm{E}_{2}$. Breast tumors developed in a dose-dependent manner (32). Tumors were induced even following implantation of $\mathrm{E}_{2}$ plus the anti-estrogen ICI-182,780 (33). These results support the hypothesis that estrogen metabolism is a crucial event in the initiation of estrogen-induced cancer.

The mutagenicity of $E_{1}\left(E_{2}\right)-3,4-Q$ was first studied in female SENCAR mice by determining the H-ras mutations induced, and the estrogen-DNA adducts formed (34). Equal amounts of the depurinating 4-OHE $\left(\mathrm{E}_{2}\right)-1-\mathrm{N} 3 \mathrm{Ade}$ and $4-\mathrm{OHE}_{1}\left(\mathrm{E}_{2}\right)-1-\mathrm{N} 7 \mathrm{Gua}$ adducts were identified in the skin, representing $>99 \%$ of the total adducts formed (34). Mutations were observed in the $\mathrm{H}$-ras oncogene within 6-12 $\mathrm{h}$ after treatment. The rapid appearance of mutations indicated that they arose by error-prone repair of the apurinic sites generated by the depurinating estrogen-DNA adducts. In a second study, female ACI rats, which are susceptible to estrogen-induced mammary tumors, were treated with $\mathrm{E}_{1}\left(\mathrm{E}_{2}\right)-3,4-\mathrm{Q}$ by intramammillary injection. Depurinating N3Ade and N7Gua adducts as well as $\mathrm{H}$-ras mutations were detected in mammary skin tissue. These results demonstrate the mutagenic activity of these estrogen metabolites (35). With multiple treatments of the mammalian cells with $4-\mathrm{OHE}_{1}\left(\mathrm{E}_{2}\right)$, a dose-dependent, statistically significant increase in mutant fraction was observed (36). The reactive quinone formed from $4-\mathrm{OHE}_{1}\left(\mathrm{E}_{2}\right), \mathrm{E}_{1}\left(\mathrm{E}_{2}\right)-3,4-\mathrm{Q}$, was similarly mutagenic. However, no mutagenicity was detected when the cells were treated with 2-OHE $\left.\mathrm{OH}_{1}\right)(36)$.

To date, three studies have been conducted in women at normal or high risk for breast cancer. The risk of developing breast cancer is measured as the ratio of estrogen-DNA adducts to their respective estrogen metabolites and conjugates. High levels of estrogen-DNA adducts have been seen in analyses of urine and serum from women that are at high risk of breast cancer $(14,37,38)$. Observation of higher levels of estrogen-DNA adducts in women at high risk for breast cancer would suggest that formation of these adducts is a causative factor in the etiology of breast cancer rather than a consequence of the disease (4). 


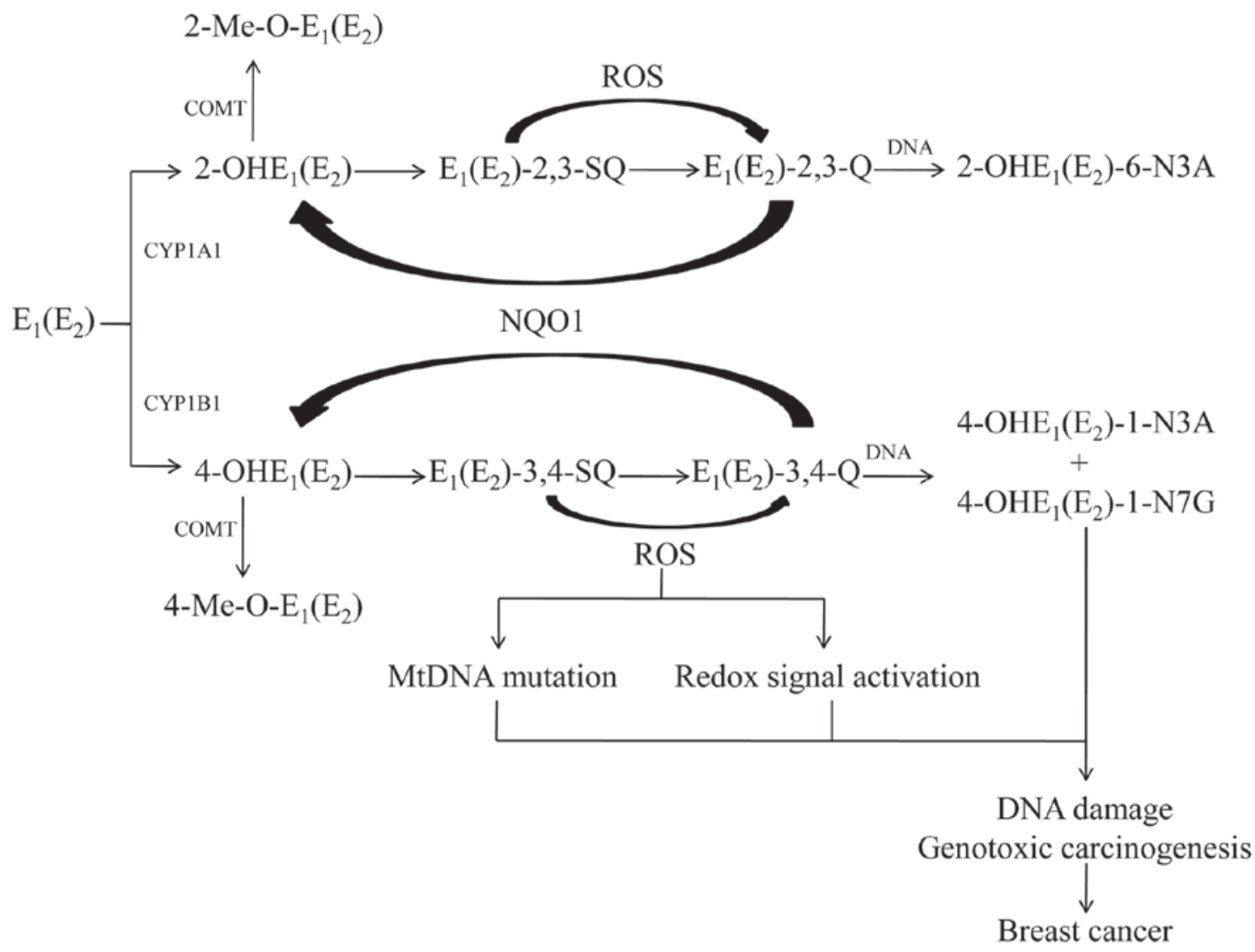

Figure 1. Metabolic pathway for estrogen carcinogenesis. ROS, reactive oxygen species; $\mathrm{E}_{1}$, estrone; $\mathrm{E}_{2,}$ 17 $\beta$-estradiol; NQO1, NAD(P)H-Quinone oxidoreductase 1; MtDNA, mitochondrial DNA; COMT, catechol-O-methyltransferase; CYP, cytochrome P450.

\section{Role of ROS in estrogen carcinogenesis}

Redox cycling via reduction of CE-Q to semiquinones, catalyzed by CYP reductase, and subsequent oxidation back to CE-Q by $\mathrm{O}_{2}$, forms super-anion radicals and then $\mathrm{H}_{2} \mathrm{O}_{2}(39)$. Estrogen-mediated high ROS accumulation serves a key role in driving carcinogenesis (40). Excessive ROS serves as an important effector to increase genomic instability and activate the redox-associated signaling pathway. Physiologically available concentrations of estrogens or estrogen metabolites directly acting on the mitochondria of mammary epithelial cells produces ROS, which subsequently enhances the phosphorylation of kinases to activate redox-sensitive transcription factors $(41,42)$. Therefore, ROS serves an important role in estrogen-induced cancer.

2- $\mathrm{OHE}_{1}\left(\mathrm{E}_{2}\right)$ and 4- $\mathrm{OHE}_{1}\left(\mathrm{E}_{2}\right)$ are highly redox active and generate ROS in breast epithelial cells (9). The prolonged exposure to estrogen aggravates mutations in mitochondrial DNA (mtDNA) and mitochondrial protein damage by inducing ROS overproduction. Previous studies have identified that instability of mtDNA induces cancer cell metastasis and triggers cancer malignant transformation, whereas ROS scavengers suppress the metastatic potential in mice via alleviation of mtDNA mutation (43). Furthermore, mutations in mtDNA altering expression and function of the mitochondrial respiratory chain was observed in breast cancer cells, blocking of estrogens attenuated the respiratory and metabolic responses and superoxide accumulation $(44,45)$. These results indicated that ROS-triggered mtDNA mutations may contribute to cancer malignant transformation. Furthermore, overproduction of ROS induced by alteration of mitochondrial metabolism is also involved in estrogen-mediated carcinogenesis via induction of oxidative DNA damage (40).

A recent study identified that ROS induced by $4-\mathrm{OHE}_{1}\left(\mathrm{E}_{2}\right)$ causes malignant transformation of MCF-10A cells, and co-treatment with 4- $\mathrm{OHE}_{1}\left(\mathrm{E}_{2}\right)$ and biological or chemical ROS scavengers prevents the tumorigenic conversion of MCF-10A cells (41). It appears that oxidant-mediated activation of redox-sensitive phosphatidylinositol 3-kinase/protein kinase B (AKT) pathways serves a pivotal role in tumor malignant transformation of healthy breast epithelial cells by estrogens (41). In addition to $\mathrm{AKT}$, the nuclear factor- $\mathrm{\kappa B}(\mathrm{NF}-\kappa \mathrm{B})$ family is another important redox transcription factor activated by ROS that has been observed during neoplastic transformation of mammary epithelial cells (46). ROS overproduced by CEs accelerates the nuclear translocation of NF- $\kappa \mathrm{B}$ by induction of IкB kinase (IKK) $\alpha$ and $-\beta$ activities (47). At the same time, inhibition of $\mathrm{NF}-\kappa \mathrm{B}$ activation by antioxidants has demonstrated a positive associated between NF- $\mathrm{KB}$-associated neoplastic transformation and ROS overproduction $(47,48)$. Excess ROS generated by repeated exposure to $4-\mathrm{OHE}_{1}\left(\mathrm{E}_{2}\right)$ causes malignancy of human mammary epithelial cells in nude mice (41).

In conclusion, estrogen induces the overproduction of ROS, which subsequently initiates multiple biological functions, including mtDNA mutation, alteration of mitochondrial metabolism, and activation of the redox-associatedsignaling pathway, thereby accelerating cell proliferation involved in tumor progression. 


\section{Association of metabolism enzyme polymorphisms in breast cancer}

Levels of 4-OHE $\mathrm{E}_{1}\left(\mathrm{E}_{2}\right)$ in breast cancer are increased compared with healthy breast tissue (14). As CYP1B1 is the key enzyme for the formation of $4-\mathrm{OHE}_{1}\left(\mathrm{E}_{2}\right)$, expression and genetic variations in CYP1B1 may influence breast cancer progression by increasing concentration of $4-\mathrm{OHE}_{1}\left(\mathrm{E}_{2}\right)$. To date, $>300$ polymorphisms have been found in CYP1B1 (49). The most common polymorphisms of CYP1B1, including Arg48Gly, Ala119Ser, Val432Leu and Asn453Ser, lead to alterations in estrogen metabolism and may influence the risk of breast cancer (49). An in vitro study demonstrated that the 4-hydroxylase activities of estradiol by Ala119Ser and Asn453Ser variants of CYP1B1 are 2-4-fold higher compared with wild-types (49). The Val432Leu variant increases CYP1B1 catalytic ability, with a subsequent elevation in $4-\mathrm{OHE}_{1}\left(\mathrm{E}_{2}\right)$ formation (50). The Asn453Ser polymorphism is associated with decreased levels of CYP1B1 cellular protein, which is associated with a reduced risk of breast cancer in postmenopausal women (51). However, the effect of CYP1B1 polymorphisms in breast cancer etiology remains controversial. It has been reported that there are no associations between Arg48Gly, Ala119Ser, Val432Leu and Asn453Ser and breast cancer risk in Polish population, but another study identified that Arg48Gly, Ala119Ser and Val432Leu variants were associated with increased breast cancer risk in the Polish population $(52,53)$. A case-control study reported that Leu432Val and Val432Val genotypes significantly increased breast cancer risk (50). Jiao et al (54) also identified that CYP1B1 432 Val variants appear to be a factor for susceptibility to breast cancer.

In contrast to $4-\mathrm{OHE}_{1}\left(\mathrm{E}_{2}\right), 2-\mathrm{OHE}_{1}\left(\mathrm{E}_{2}\right)$ is weakly carcinogenic or has protective activity. An increase in CYP1A1 activity directs $\mathrm{CEs}$ toward $2-\mathrm{OHE}_{1}\left(\mathrm{E}_{2}\right)$ and away from the genotoxic 4-OHE $1\left(\mathrm{E}_{2}\right)(11,19)$. T3801C, T3205C, A2455 G and $\mathrm{C} 2453 \mathrm{~A}$ variants in CYP1A1 have been studied in regard to their potential implication in breast cancer risk. The two former variants are located in the 3'-noncoding region, whereas the latter two lead to amino acid substitutions in exon 7 (Ile462Val and Thr461 Asp, respectively), which increase CYP1A1 activity (55). Chen et al (56) demonstrated that the A $2455 \mathrm{G} \mathrm{G} / \mathrm{G}$ genotype is associated with increased breast cancer risk in East-Asians. Additionally, Caucasian subjects carrying the A2455 $\mathrm{G}$ allele also exhibited an elevated breast cancer risk (57). T3801C, T3205C and C2453A variants were not associated with breast cancer risk (57).

COMT is a phase II protective enzyme in that methylation of the catechol metabolites blocks oxidative metabolism to reactive quinones, and thus is protective against formation of the depurinating adducts and ROS. A widely studied single nucleotide polymorphism (SNP) in exon 4 results in the amino acid substitution of Val with Met, termed Val158Met (16). Compared with wild-types, the Met158 variant demonstrates thermo instability; thus, COMT activity is reduced in cells expressing Met158 (58). Previous studies have identified that the Val158Met variant affects protein stability, and altered conformation renders it more susceptible to recognition by the cellular protein degradation processes, thus reducing cell activity $(58,59)$. Meta-analyses have examined the influence of COMT on breast cancer incidence in women. The results suggested that a Val158Met polymorphism in the COMT gene may be a risk factor for breast cancer in the Chinese population $(60,61)$. However, Li et al (62) suggested that the COMT Val158Met polymorphism is not a risk factor for breast cancer in the Asian population.

However, numerous studies have been performed to investigate the association of these polymorphisms with susceptibility to breast cancer. However, the results of these studies remain conflicting. Together, these results demonstrate that without some measure of enzyme expression or activity, it is difficult to predict and interpret results from these types of SNP-association studies.

\section{Conclusion}

Increasing studies have identified that excessive exposure to estrogens is associated with increased breast cancer risk. Results from in vivo and in vitro studies have indicated that oxidative metabolism of estrogens serves a major role in the initiation of breast cancer. The oxidative metabolism of estrogens to reactive quinones causes both formation of depurinating adducts and production of ROS, which are associated with breast cancer progression. The regulation of metabolism enzymes, which are responsible for estrogen metabolism, are critical for the homeostasis of estrogen. SNPs in enzymes may influence the risk of breast cancer, but the results remain conflicting. Future investigations into the role of estrogen metabolism, phase I and phase II involvement in estrogen metabolism, and their SNPs are required to measure specific biomarkers of metabolites. This may involve determination of the levels of the specific adenine and guanine DNA adducts and markers of oxidative DNA damage, detectable in urine and plasma. Through this approach, the role of SNPs in the formation and inactivation of enzymes, including CYP1A1, CYP1B1 and COMT, maybe determined.

\section{Acknowledgements}

This review was supported by the National Scientific Foundation of China (no. 81603201), and the Funds for outstanding young scholars in Chongqing Medical University (no. CYYQ201401).

\section{References}

1. DeSantis C, Siegel R, Bandi P and Jemal A: Breast cancer statistics. CA Cancer J Clin 61: 409-418, 2011.

2. Santen RJ, Boyd NF, Chlebowski RT, Cummings S, Cuzick J, Dowsett M, Easton D, Forbes JF, Key T, Hankinson SE, et al: Critical assessment of new risk factors for breast cancer: Considerations for development of an improved risk prediction model. Endocr Relat Cancer 14: 169-187, 2007.

3. Hofseth LJ, Raafat AM, Osuch JR, Pathak DR, Slomski CA and Haslam SZ: Hormone replacement therapy with estrogen or estrogen plus medroxyprogesterone acetate is associated with increased epithelial proliferation in the normal postmenopausal breast. J Clin Endocrinol Metab 84: 4559-4565, 1999.

4. Cavalieri E and Rogan E: The molecular etiology and prevention of estrogen-initiated cancers: Ockham's Razor: Pluralitas non est ponenda sine necessitate. Plurality should not be posited without necessity. Mol Aspects Med 36: 1-55, 2014.

5. Devanesan P, Santen RJ, Bocchinfuso WP, Korach KS, Rogan EG and Cavalieri E: Catechol estrogen metabolites and conjugates in mammary tumors and hyperplastic tissue from estrogen receptor-alpha knock-out (ERKO)/Wnt-1 mice: Implications for initiation of mammary tumors. Carcinogenesis 22: 1573-1576, 2001. 
6. Cavalieri EL, Stack DE, Devanesan PD, Todorovic R, Dwivedy I, Higginbotham S, Johansson SL, Patil KD, Gross ML, Gooden JK, et al: Molecular origin of cancer: Catechol estrogen-3,4-quinones as endogenous tumor initiators. Proc Natl Acad Sci USA 94: 10937-10942, 1997.

7. Li KM, Todorovic R, Devanesan P, Higginbotham S, Köfeler H, Ramanathan R, Gross ML, Rogan EG and Cavalieri EL: Metabolism and DNA binding studies of 4-hydroxyestradiol and estradiol-3,4-quinone in vitro and in female ACI rat mammary gland in vivo. Carcinogenesis 25: 289-297, 2004.

8. Cavalieri EL and Rogan EG: Depurinating estrogen-DNA adducts in the etiology and prevention of breast and other human cancers. Future Oncol 6: 75-91, 2010.

9. Fussell KC, Udasin RG, Smith PJ, Gallo MA and Laskin JD Catechol metabolites of endogenous estrogens induce redox cycling and generate reactive oxygen species in breast epithelial cells. Carcinogenesis 32: 1285-1293, 2011.

10. Valko M, Rhodes CJ, Moncol J, Izakovic M and Mazur M: Free radicals, metals and antioxidants in oxidative stress-induced cancer. Chem Biol Interact 160: 1-40, 2006.

11. Lee AJ, Cai MX, Thomas PE, Conney AH and Zhu BT: Characterization of the oxidative metabolites of 17beta-estradiol and estrone formed by 15 selectively expressed human cytochrome p450 isoforms. Endocrinology 144: 3382-3398, 2003

12. Jefcoate CR, Liehr JG, Santen RJ, Sutter TR, Yager JD, Yue W, Santner SJ, Tekmal R, Demers L, Pauley R, et al: Tissue-specific synthesis and oxidative metabolism of estrogens. J Natl Cancer Inst Monogr: 95-112, 2000.

13. Rahman M, Lax SF, Sutter CH, Tran QT, Stevens GL, Emmert GL, Russo J, Santen RJ and Sutter TR: CYP1B1 is not a major determinant of the disposition of aromatase inhibitors in epithelial cells of invasive ductal carcinoma. Drug Metab Dispos 36: 963-970, 2008.

14. Pruthi S, Yang L, Sandhu NP, Ingle JN, Beseler CL, Suman VJ, Cavalieri EL and Rogan EG: Evaluation of serum estrogen-DNA adducts as potential biomarkers for breast cancer risk. J Steroid Biochem Mol Biol 132: 73-79, 2012

15. Salama SA, Kamel M, Awad M, Nasser AH, Al-Hendy A, Botting S and Arrastia C: Catecholestrogens induce oxidative stress and malignant transformation in human endometrial glandular cells: Protective effect of catechol-O-methyltransferase. Int J Cancer 123: 1246-1254, 2008.

16. Yager JD: Catechol-O-methyltransferase: Characteristics, polymorphisms and role in breast cancer. Drug Discov Today Dis Mech 9: e41-e46, 2012

17. Lavigne JA, Goodman JE, Fonong T, Odwin S, He P, Roberts DW and Yager JD: The effects of catechol-O-methyltransferase inhibition on estrogen metabolite and oxidative DNA damage levels in estradiol-treated MCF-7 cells. Cancer Res 61: 7488-7494, 2001

18. Zahid M, Saeed M, Lu F, Gaikwad N, Rogan E and Cavalieri E: Inhibition of catechol-O-methyltransferase increases estrogen-DNA adduct formation. Free Radic Biol Med 43: 1534-1540, 2007.

19. Zhu BT and Conney AH: Is 2-methoxyestradiol an endogenous estrogen metabolite that inhibits mammary carcinogenesis? Cancer Res 58: 2269-2277, 1998.

20. Gaikwad NW, Rogan EG and Cavalieri EL: Evidence from ESI-MS for NQO1-catalyzed reduction of estrogen ortho-quinones. Free Radic Biol Med 43: 1289-1298, 2007.

21. Cavalieri E, Rogan E and Chakravarti D: The role of endogenous catechol quinones in the initiation of cancer and neurodegenerative diseases. Methods Enzymol 382: 293-319, 2004.

22. Cavalieri EL and Rogan EG: A unifying mechanism in the initiation of cancer and other diseases by catechol quinones. Ann N Y Acad Sci 1028: 247-257, 2004

23. Stack DE, Li G, Hill A and Hoffman N: Mechanistic insights into the Michael addition of deoxyguanosine to catechol estrogen-3,4-quinones. Chem Res Toxicol 21: 1415-1425, 2008.

24. Bolton JL and Shen L: p-Quinone methides are the major decomposition products of catechol estrogen o-quinones. Carcinogenesis 17: 925-929, 1996.

25. Zahid M, Kohli E, Saeed M, Rogan E and Cavalieri E: The greater reactivity of estradiol-3,4-quinone vs estradiol-2,3-quinone with DNA in the formation of depurinating adducts: Implications for tumor-initiating activity. Chem Res Toxicol 19: 164-172, 2006.

26. Lu F, Zahid M, Saeed M, Cavalieri EL and Rogan EG: Estrogen metabolism and formation of estrogen-DNA adducts in estradiol-treated MCF-10F cells. The effects of 2,3,7,8-tetrachlorodibenzo-p-dioxin induction and catechol-O-methyltransferase inhibition. J Steroid Biochem Mol Biol 105: 150-158, 2007.
27. Lu F, Zahid M, Wang C, Saeed M, Cavalieri EL and Rogan EG Resveratrol prevents estrogen-DNA adduct formation and neoplastic transformation in MCF-10F cells. Cancer Prev Res 1: 135-145, 2008

28. Saeed M, Rogan E, Fernandez SV, Sheriff F, Russo J and Cavalieri E: Formation of depurinating N3Adenine and N7Guanine adducts by MCF-10F cells cultured in the presence of 4-hydroxyestradiol. Int J Cancer 120: 1821-1824, 2007.

29. Russo J and Russo IH: Genotoxicity of steroidal estrogens. Trends Endocrinol Metab 15: 211-214, 2004.

30. Russo J, Hasan Lareef M, Balogh G, Guo S and Russo IH: Estrogen and its metabolites are carcinogenic agents in human breast epithelial cells. J Steroid Biochem Mol Biol 87: 1-25, 2003

31. Lareef MH, Garber J, Russo PA, Russo IH, Heulings R and Russo J: The estrogen antagonist ICI-182-780 does not inhibit the transformation phenotypes induced by 17-beta-estradiol and 4-OH estradiol in human breast epithelial cells. Int J Oncol 26: 423-429, 2005

32. Yue W, Santen RJ, Wang JP, Li Y, Verderame MF, Bocchinfuso WP, Korach KS, Devanesan P, Todorovic R, Rogan EG and Cavalieri EL: Genotoxic metabolites of estradiol in breast: Potential mechanism of estradiol induced carcinogenesis. J Steroid Biochem Mol Biol 86: 477-486, 2003.

33. Santen R, Cavalieri E, Rogan E, Russo J, Guttenplan J, Ingle J and Yue W: Estrogen mediation of breast tumor formation involves estrogen receptor-dependent, as well as independent, genotoxic effects. Ann NY Acad Sci 1155: 132-140, 2009.

34. Chakravarti D, Mailander PC, Li KM, Higginbotham S, Zhang HL, Gross ML, Meza JL, Cavalieri EL and Rogan EG: Evidence that a burst of DNA depurination in SENCAR mouse skin induces error-prone repair and forms mutations in the $\mathrm{H}$-ras gene. Oncogene 20: 7945-7953, 2001.

35. Mailander PC, Meza JL, Higginbotham S and Chakravarti D: Induction of A.T to G.C mutations by erroneous repair of depurinated DNA following estrogen treatment of the mammary gland of ACI rats. J Steroid Biochem Mol Biol 101: 204-215, 2006.

36. Zhao Z, Kosinska W, Khmelnitsky M, Cavalieri EL, Rogan EG, Chakravarti D, Sacks PG and Guttenplan JB: Mutagenic activity of 4-hydroxyestradiol, but not 2-hydroxyestradiol, in BB rat2 embryonic cells and the mutational spectrum of 4-hydroxyestradiol. Chem Res Toxicol 19: 475-479, 2006.

37. Gaikwad NW, Yang L, Muti P, Meza JL, Pruthi S, Ingle JN, Rogan EG and Cavalieri EL: The molecular etiology of breast cancer: Evidence from biomarkers of risk. Int J Cancer 122 1949-1957, 2008

38. Gaikwad NW, Yang L, Pruthi S, Ingle JN, Sandhu N, Rogan EG and Cavalieri EL: Urine biomarkers of risk in the molecular etiology of breast cancer. Breast Cancer 3: 1-8, 2009.

39. Cavalieri E, Chakravarti D, Guttenplan J, Hart E, Ingle J, Jankowiak R, Muti P, Rogan E, Russo J, Santen R and Sutter T: Catechol estrogen quinones as initiators of breast and other human cancers: Implications for biomarkers of susceptibility and cancer prevention. Biochim Biophys Acta 1766: 63-78, 2006.

40. Tian H, Gao Z, Wang G, Li H and Zheng J: Estrogen potentiates reactive oxygen species (ROS) tolerance to initiate carcinogenesis and promote cancer malignant transformation. Tumour Biol 37: 141-150, 2016

41. Okoh VO, Felty Q, Parkash J, Poppiti R and Roy D: Reactive oxygen species via redox signaling to PI3K/AKT pathway contribute to the malignant growth of 4-hydroxy estradiol-transformed mammary epithelial cells. PLoS One 8: e54206, 2013.

42. Felty Q, Xiong WC, Sun D, Sarkar S, Singh KP, Parkash J and Roy D: Estrogen-induced mitochondrial reactive oxygen species as signal-transducing messengers. Biochemistry 44 : 6900-6909, 2005.

43. Ishikawa $K$, Takenaga $K$, Akimoto $M$, Koshikawa N, Yamaguchi A, Imanishi H, Nakada K, Honma Y and Hayashi J: ROS-generating mitochondrial DNA mutations can regulate tumor cell metastasis. Science 320: 661-664, 2008.

44. Doan VD, Gagnon S and Joseph V: Prenatal blockade of estradiol synthesis impairs respiratory and metabolic responses to hypoxia in newborn and adult rats. Am J Physiol Regul Integr Comp Physiol 287: R612-R618, 2004.

45. Tan DJ, Bai RK and Wong LJ: Comprehensive scanning of somatic mitochondrial DNA mutations in breast cancer. Cancer Res 62: 972-976, 2002.

46. Kim DW, Sovak MA, Zanieski G, Nonet G, Romieu-Mourez R, Lau AW, Hafer LJ, Yaswen P, Stampfer M, Rogers AE, et al: Activation of NF-kappaB/Rel occurs early during neoplastic transformation of mammary cells. Carcinogenesis 21: 871-879, 2000 . 
47. Park SA, Na HK, Kim EH, Cha YN and Surh YJ: 4-hydroxyestradiol induces anchorage-independent growth of human mammary epithelial cells via activation of IkappaB kinase: Potential role of reactive oxygen species. Cancer Res 69: 2416-2424, 2009.

48. Benhar M, Engelberg D and Levitzki A: ROS, stress-activated kinases and stress signaling in cancer. EMBO Rep 3: 420-425, 2002.

49. Hanna IH, Dawling S, Roodi N, Guengerich FP and Parl FF: Cytochrome P450 1B1 (CYP1B1) pharmacogenetics: Association of polymorphisms with functional differences in estrogen hydroxylation activity. Cancer Res 60: 3440-3444, 2000.

50. Delort L, Satih S, Kwiatkowski F, Bignon YJ and BernardGallon DJ: Evaluation of breast cancer risk in a multigenic model including low penetrance genes involved in xenobiotic and estrogen metabolisms. Nutr Cancer 62: 243-251, 2010.

51. Bandiera S, Weidlich S, Harth V, Broede P, Ko Y and Friedberg T: Proteasomal degradation of human CYP1B1: Effect of the Asn453Ser polymorphism on the post-translational regulation of CYP1B1 expression. Mol Pharmacol 67: 435-443, 2005.

52. Matyjasik J, Cybulski C, Masojé B, Jakubowska A, SerranoFernandez P, Górski B, Debniak T, Huzarski T, Byrski T, Gronwald J, et al: CYP1B1 and predisposition to breast cancer in Poland. Breast Cancer Res Treat 106: 383-388, 2007.

53. Gaudet MM, Chanock S, Lissowska J, Berndt SI, Yang XR, Peplonska B, Brinton LA, Welch R, Yeager M, BardinMikolajczak A, et al: Genetic variation of Cytochrome P450 1B1 (CYP1B1) and risk of breast cancer among Polish women. Pharmacogenet Genomics 16: 547-553, 2006.

54. Jiao H, Liu C, Guo W, Peng L, Chen Y and Martin FL: Association of CYP1B1 Polymorphisms with Breast Cancer: A Case-Control Study in the Han Population in Ningxia Hui Autonomous Region, P. R. China. Biomark Insights 5: 21-27, 2010.
55. Masson LF, Sharp L, Cotton SC and Little J: Cytochrome P-450 1A1 gene polymorphisms and risk of breast cancer: A HuGE review. Am J Epidemiol 161: 901-915, 2005.

56. Chen C, Huang Y, Li Y, Mao Y and Xie Y: Cytochrome P450 1A1 (CYP1A1) T3801C and A2455G polymorphisms in breast cancer risk: A meta-analysis. J Hum Genet 52: 423-435, 2007.

57. Sergentanis TN and Economopoulos KP: Four polymorphisms in cy tochrome P450 1A1 (CYP1A1) gene and breast cancer risk: A meta-analysis. Breast Cancer Res Treat 122: 459-469, 2010.

58. Shield AJ, Thomae BA, Eckloff BW, Wieben ED and Weinshilboum RM: Human catechol O-methyltransferase genetic variation: Gene resequencing and functional characterization of variant allozymes. Mol Psychiatry 9: 151-160, 2004.

59. Doyle AE and Yager JD: Catechol-O-methyltransferase: Effects of the val108met polymorphism on protein turnover in human cells. Biochim Biophys Acta 1780: 27-33, 2008.

60. Tian C, Liu L, Yang X, Wu H and Ouyang Q: The Val158Met polymorphism in the COMT gene is associated with increased cancer risks in Chinese population. Tumour Biol 35: 3003-3008, 2014.

61. Wan GX, Cao YW, Li WQ, Li YC and Li F: The catechol-O-methyltransferase Val158Met polymorphism contributes to the risk of breast cancer in the chinese population: an updated meta-analysis. J Breast Cancer 17: 149-156, 2014.

62. Li K, Li W and Zou H: Catechol-O-methyltransferase Val158Met polymorphism and breast cancer risk in Asian population. Tumour Biol 35: 2343-2350, 2014. 